OPEN ACCESS

Edited by:

Peter Neubauer,

Technische Universität Berlin

Germany

Reviewed by:

Grzegorz Wegrzyn,

University of Gdansk, Poland

Antti IImari Vasala,

BioSilta Oy, Finland

Florian Glauche

Technische Universität Berlin,

Germany

Marcin Los,

University of Gdansk, Poland

*Correspondence:

Sukant Khurana,

Department of Biological Sciences,

Indian Institute of Science Education

and Research Kolkata, Prefab

Building 2, Mohanpur, Nadia 741252 ,

Kolkata, India

sukantkhurana@gmail.com

Specialty section

This article was submitted to

Microbiotechnology, Ecotoxicology and Bioremediation

a section of the journal

Frontiers in Microbiology

Received: 11 April 2015

Accepted: 26 June 2015

Published: 23 July 2015

Citation:

Das N, Tripathi N, Basu S, Bose C,

Maitra S and Khurana S (2015)

Progress in the development of gelling

agents for improved culturability of

microorganisms.

Front. Microbiol. 6:698.

doi: 10.3389/fmich.2015.00698

\section{Progress in the development of gelling agents for improved culturability of microorganisms}

\author{
Nabajit Das ${ }^{1}$, Naveen Tripathi ${ }^{1}$, Srijoni Basu ${ }^{1}$, Chandra Bose ${ }^{1}$, Susmit Maitra ${ }^{2}$ and \\ Sukant Khurana ${ }^{1 *}$ \\ ${ }^{1}$ Department of Biological Sciences, Indian Institute of Science Education and Research Kolkata, Kolkata, India, ${ }^{2}$ School of \\ Biotechnology, Kalinga Institute of Industrial Technology University, Bhubaneswar, India
}

Gelling agents are required for formulating both solid and semisolid media, vital for the isolation of microorganisms. Gelatin was the first gelling agent to be discovered but it soon paved the way for agar, which has far superior material qualities. Source depletion, issues with polymerase-chain-reaction and inability to sustain extermophiles etc., necessitate the need of other gelling agents. Many new gelling agents, such as xantham gum, gellan gum, carrageenan, isubgol, and guar gum have been formulated, raising the hopes for the growth of previously unculturable microorganisms. We evaluate the progress in the development of gelling agents, with the hope that our synthesis would help accelerate research in the field.

Keywords: agar, gelatin, xanthan gum, guar gum, gellan gum, isabgol, carrageenan, katira gum

\section{Introduction}

Gelling agents are added to the liquid microbial media to convert them into semi-solid or solid media. Generally some colloidal polysaccharides and certain proteins of microbial and plant origin act as solidifiers or stabilizers in the medium by forming continuous three-dimensional molecular network. Gelling agents provide firmness to the medium and influence its diffusion characteristics. Diffusion rate is dependent on the viscosity of the medium, which subsequently depends on the concentration and physicochemical characteristics of the agent (Ackers and Steere, 1962; Palaniraj and Jayaraman, 2011). Certain gelling agents can reverse between liquid and gel state depending on the temperature, a property that adds much to their desirability. A good solidifier tends to be colorless, odorless and a good retainer of moisture.

Several mesophiles and extremophiles are currently unculturable or poorly culturable due to the lack of proper biotic and abiotic factors. Each gelling agent has a limited range of $\mathrm{pH}$ and temperature of optimal functioning and different gelling agents can be degraded by a different set of microorganisms, necessitating the need of several gelling agents. In recent times, traditional sources of gelling agents are being overused, further necessitating the need of new gelling agents.

Recent work on gelling agents that can withstand variety of temperatures and pressures have helped in culturing newer microbes, including few extremophiles, which could otherwise not be grown (Becker et al., 1998; Jain et al., 2005). Despite important applications in microbiology, there is a lack of synthesis of information about major gelling agents at one place. We attempt to fill that lacuna by covering gelling agents, which support the growth of mesophiles and also agents, which support the growth of extremophiles. 
In Figure 1 we present the timeline of discovery of first gelling agents: gelatin and agar, followed by subsequent important developments. After several decades of the discovery of agar and gelatin, in 1950s, another alternative agent, Xanthan gum was reported to be of use. It was derived from a bacterium called Xanthomonas campestris (García-Ochoa et al., 2000; Bellini and Caliari, 2014). Two other gelling agents came in two successive years: carrageenan in 1977 (Lines, 1977; Jagdale and Pawar, 2014; Kuo et al., 2014; Razavi et al., 2014) and gellan gum in 1978 (Nampoothiri et al., 2003; Jamshidian et al., 2014). Isubgol was proposed as another alternative in the year 1997 (Jansson et al., 1983; Jain et al., 1997; Harding et al., 2004; Fialho et al., 2008), which was followed by the latest of its kind guar gum in 2005 (Jain et al., 2005; Kirchmajer et al., 2014). Figure 1 also represents the source of the major gelling agents.

\section{Gelatin and Agar: the First Gelling Agents}

Solid media, which is achieved by the addition of gelling agents to the liquid broth, is more suited for the separation and isolation of microorganisms than liquid media. Gelatin was used to obtain the first solid media in 1881 by Robert Koch (Poppe, 1997; Jain, 2011; Petrovski and Tillett, 2012). Its digestion by bacteria and melting temperature at $37^{\circ} \mathrm{C}$ limited its use. These problems associated with gelatin propelled the search for alternative agents. The use of agar as an alternative to gelatin was first proposed by Angelina Hesse the wife of Walther Hesse, an associate of Koch in 1882 to prepare solid culture (McLachlan, 1985; Becker et al., 1998).

Various advantages of agar over gelatin made it popular, as it is stable over a wide range of temperature (solidification temperature between 32 and $42^{\circ} \mathrm{C}$ and melting temperature around $85^{\circ} \mathrm{C}$ ) and thus is suitable for the growth of mesophilic organisms. The firmness of media increases directly in proportion to the concentration of agar (Kang et al., 1982; Giavasis et al., 2000; Sá-Correia et al., 2002; Nampoothiri et al., 2003; Jain, 2011). Additionally agar has good diffusion characteristics (Manjanna et al., 2010; Petrovski and Tillett,
2012) and has good clarity, low adhesiveness and is metabolically inert (McLachlan, 1985; Henderson and Kinnersley, 1988; Petrovski and Tillett, 2012). Agarases are a class of enzymes that are capable of degrading agar. A number of agarase-producing microorganisms, present mainly in the marine environments have been reported to degrade and utilize agar (Stanier, 1941; Ohta et al., 2004; Bannikova et al., 2008; Miyazaki et al., 2008). A novel agar-degrading bacterium, designated as strain KA5-BT has also been isolated from the soil (Sakai et al., 2014). The $\beta$ - $(1 \rightarrow 4)$ linkage of agarose is hydrolyzed by most agarases yielding oligosaccharides. In Pseudoalteromonas atlantica (Day and Yaphe, 1975; Groleau and Yaphe, 1977), a well characterized agarolytic system the extracellular endo- $\beta$-agarase I depolymerizes agarose to neoagarotetraose.

Extensive usage of agar in laboratories has affected its natural sources, such as Gelidium sp., Gracillaria sp., and Pterocladia sp. (Lin and Casida, 1984; McLachlan, 1985; Schmidt and Rath, 2003; Kirchmajer et al., 2014) and increased its cost. Food grade agar has also been reported as a low-cost alternative in the preparation of solid microbiological media (Harding et al., 2004; Fialho et al., 2008; Petrovski and Tillett, 2012). The food grade agar is comparable to bacteriological agar in terms of its gelling and stability properties. However, the media produced with food grade agar have less clarity than that produced with bacteriological agar (Kang et al., 1982; Petrovski and Tillett, 2012).

\section{Development of Alternative Gelling Agents}

Many alternative gelling agents were discovered with time, such as carrageenan (Lines, 1977), kappa-carrageenan (Abbott and Chapman, 1981; Morris et al., 2012), gellan gum (Kang et al., 1982; Shungu et al., 1983; Kuo et al., 2014), isubgol (Shungu et al., 1983; Lin and Casida, 1984; Harris, 1985; Marteinsson et al., 1997; Babbar and Jain, 1998; Sahay, 1999; Atici et al., 2008; Ozel et al., 2008), guar gum (Shimomura and Kamada, 1986; Huang et al., 1995; Shigeta et al., 1996; Chen et al., 1999; Jain et al., 2005) and xanthan gum (Giavasis et al., 2000; Babbar and Jain,

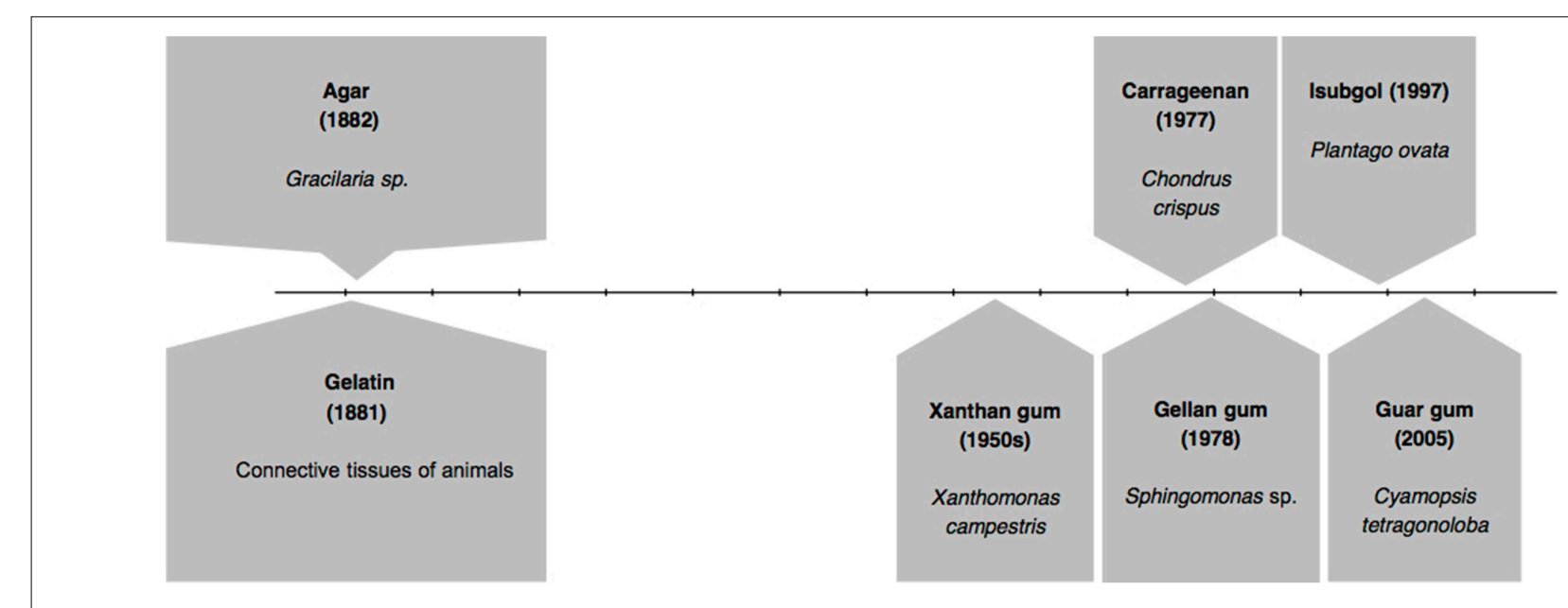

FIGURE 1 | Timeline of discovery of various gelling agents. 
2006; Prajapati et al., 2013). The building blocks and properties of these agents are presented in Table 1. Gelling agents have several applications in animal and plant cell culture, pharmaceutical and food industry and we expect cross fertilization from these fields for the development of novel gelling agents needed in microbial media.

\section{Xanthan Gum}

Xanthan gum, a water soluble pentasaccharide produced by the fermentation of carbon sources, using plant-pathogenic bacterium Xanthomonas campestris (Paul et al., 1986; Kubo, 2003; Palaniraj and Jayaraman, 2011), consists of D-glucosyl, D-mannosyl and D-glucuronyl acid residues (Lines, 1977; Becker et al., 1998; Datta et al., 2011). Prosthecate bacteria Verrucomicrobium sp. GD, which has been isolated from activated sludge degrades xanthan (Muchová et al., 2009). Red pigmented gram positive bacteria can also degrade xanthan (Kennedy and Sutherland, 1994). Salt tolerant bacteria especially Bacillus species produces an inducible enzyme having extracellular xanthan degrading activity (Hou et al., 1986). Xanthan degradation leads to products like glucose, glucoronic acid, mannose, pyruvate mannose, acetylated mannose, and unidentified oligosaccharide and polysaccharide (Cadmus et al., 1982). Xanthan gum on its own does not form good gels but the gelling efficacy of Xanthan gum increases in combination with agar (McLean and Williamson, 1979; Greer and Yaphe, 1984; Barbeyron et al., 1998, 2000; Jain, 2011). This can drive decrease in agar usage and hence lower costs.

Due to its soft texture, xanthan gum is widely used as a thickener or viscosifier in both food and non-food industries. It also works as a stabilizer for a wide variety of suspensions, emulsions and foams (Becker et al., 1998; Michel et al., 2003). Xanthan gum, in combination with chitosan membranes, is used in the treatment of dermo-epidermal wounds (Michel et al., 2003; Bellini and Caliari, 2014). Various reports suggest its wide range of applications in pharmaceuticals (Gardin and Pauss, 2001; Jagdale and Pawar, 2014; Kuo et al., 2014; Razavi et al., 2014) and cosmetic industries (Jianlong and Yi, 1999; Jamshidian et al., 2014).

\section{Gellan Gum}

Gellan gum, a water soluble exo-polysaccharide produced by the bacterium Sphingomonas elodea (Jansson et al., 1983; Jain et al., 1997; Sahay, 1999; Harding et al., 2004; Fialho et al., 2008; Ozel et al., 2008), forms clear gels in the presence of multivalent cations (Jain, 2011; Kirchmajer et al., 2014). Industrially, it is inducibly produced by different strains of Sphingomonas paucimobilis (Kang et al., 1982; Giavasis et al., 2000; Sá-Correia et al., 2002; Nampoothiri et al., 2003; Sharma and Mazumder, 2014). Production of gellan gum by bacteria depends on several factors such as temperature, $\mathrm{pH}$, stirring rate, oxygen transfer and composition of the fermentive medium. Gellan gum can be of few types that includes deacetylated, clarified and native gums (Manjanna et al., 2010) and is sold under different trade names such as Gelrite and Kelcogel (Lin and Casida, 1984; Schmidt and Rath, 2003; Kirchmajer et al., 2014). In its native form, it is a linear anionic exopolysaccharide composed of a tetrasaccharide repeat unit of two molecules of D-glucose, one of L-rhamnose and one of D-glucuronic acid (Harding et al., 2004; Fialho et al., 2008). It gels faster and of higher clarity as compared to agar (Kang et al., 1982). Stronger gels of gellan gum are formed if cations are present during solution to gel transition (Morris et al., 2012). Paenibacillus sp. isolated from activated sludge degrades gellan (Muchová et al., 2009). Red pigmented gram positive bacteria can also degrade gellan (Kennedy and Sutherland, 1994). High thermal stability of gellan gum makes it an ideal medium for growth of several thermophiles, such as thermophilic Bacillus sp., Methanobacterium sp., and Methanobrevibacter sp., and bacteria belonging to the genus Thermotogales (Shungu et al., 1983; Lin and Casida, 1984; Harris, 1985; Marteinsson et al., 1997).

In plant tissue culture media, gellan gum is used as a substitute to agar (Shimomura and Kamada, 1986; Huang et al., 1995; Shigeta et al., 1996; Chen et al., 1999). Gellan gum has been reported to have potential applications in the production of

TABLE 1 | Properties of various gelling agents.

\begin{tabular}{|c|c|c|}
\hline Agent name & Building components & Characteristic feature \\
\hline Gelatin & Glycine, proline, hydroxyproline & Melts at $37^{\circ} \mathrm{C}$; Stable over a narrow temperature range; Digestible by several bacteria \\
\hline Agar & Linear polysaccharide of agarose and agaropectin & $\begin{array}{l}\text { Melts at } 85^{\circ} \mathrm{C} \text { and thus used for growing mesophiles; Stable over a wide temperature } \\
\text { range; No toxic bacterial inhibitors; Forms a clear gel }\end{array}$ \\
\hline Gellan gum & $\begin{array}{l}\text { A tetrasachharide of two D-Glucose, L-rhamnose, D } \\
\text { glucoronic acid }\end{array}$ & $\begin{array}{l}\text { Melts at } 110^{\circ} \mathrm{C} \text { and can be used for growing thermophiles; Forms stable gel at very low } \\
\text { concentration; Forms a gel of higher clarity as compared to other agents }\end{array}$ \\
\hline Xanthan gum & $\begin{array}{l}\text { Pentasaccharide of two glucose, two mannose and } \\
\text { glucoronic Acid }\end{array}$ & $\begin{array}{l}\text { Melts at } 270^{\circ} \mathrm{C} \text { and can be used for growing various fungi and bacteria; Stable over a } \\
\text { wide range of temperature and } \mathrm{pH}\end{array}$ \\
\hline Guar gum & Galactomannan (galactose and mannose) & $\begin{array}{l}\text { Melts at } 220^{\circ} \mathrm{C} \text { and can be used for growing various fungi and bacteria; Highly soluble; } \\
\text { High viscosity restricts its use; Degradable at lower } \mathrm{pH} \text {; Poor clarity due to presence of } \\
\text { impurities }\end{array}$ \\
\hline Isubgol & $\begin{array}{l}\text { Xylose, arabinose, galacturonic acid and traces of } \\
\text { rhamnose and galactose }\end{array}$ & $\begin{array}{l}\text { Melts at temperature }>100^{\circ} \mathrm{C} \text {; Stable in gel form; No cracking or drying problems; Forms } \\
\text { gel even in cold water }\end{array}$ \\
\hline Carrageenan & $\begin{array}{l}\text { Alternate units of d-galactose and 3, 6-anhydro-galactose } \\
\text { joined by a-1, } 3 \text { and B-1,4-glycosidic linkage. }\end{array}$ & $\begin{array}{l}\text { Melts around a temperature range of } 50-80^{\circ} \mathrm{C} \text {; Suitable for the growth of alkaliphiles as } \\
\text { remains stable even in high } \mathrm{pH} \text { value }\end{array}$ \\
\hline
\end{tabular}


capsules, films and fibers, as well as dental and personal care products (Giavasis et al., 2000; Prajapati et al., 2013). Gellan gum is also used for microencapsulation, cell immobilization and in controlled drug release (Paul et al., 1986; Kubo, 2003).

\section{Carrageenan}

Carrageenan, a gelatinous hydrocolloid extracted from the cell wall of marine algae Chondrus crispus, acts as a gelling substitute for agar in bacteriological media, especially the K salt of carrageenan (Lines, 1977; Datta et al., 2011). Carrageenans come in various molecular forms (McLean and Williamson, 1979; Greer and Yaphe, 1984; Barbeyron et al., 1998, 2000). Carrageenans are made up of repeating units of d-galactose residues. The connecting link between two dgalactose consists of alternate alpha $(1 \rightarrow 3)$ and beta $(1 \rightarrow 4)$ linkages (Michel et al., 2003). Both, kappa- and iota-carrageenan chains can adopt ordered conformations, which leads to the formation of crystalline fibers composed of aggregates of double-stranded helices (Michel et al., 2003). Pseudoalteromonas carrageenovora produce enzymes for the hydrolysis of iota, Kappa and lambda carrageenan by the breakage of $\beta$ 1,4-linkage (Henares et al., 2010). l-carrageenan specific extracellular carrageenase (Greer and Yaphe, 1984) is produced by Alteromonas fortis. Z. galactanivorans, a flavobacteria isolated from the red alga Delesseria sanguinea in Roscoff (Potin et al., 1991), secretes one $\kappa$-carrageenase (Potin et al., 1991) and one 1-carrageenase (Barbeyron et al., 2000). All the known carrageenases specifically cleave the $\beta-(1 \rightarrow 4)$ linkage of their respective substrates. A combination of kappacarrageenan and gelatin has also been found to support the co-immobilization of aerobic and anaerobic bacteria (Gardin and Pauss, 2001).

The development of chitosan-carrageenan nanoparticles and polymers of alginate and carrageenan have potential applications in tissue engineering and regenerative medicine (Jianlong and $\mathrm{Yi}$, 1999).

\section{Isubgol}

Psyllium (Isubgol), a colloidal polysaccharide successfully used as an alternative gelling agent in tissue culture media has also been used in microbial culturing (Jain et al., 1997; Sahay, 1999; Ozel et al., 2008). It remains highly viscous at high temperatures and thus poses a problem in the adjustment of $\mathrm{pH}$ and the dispensing of media to the culture vessel (Jain, 2011). Studies have revealed that Isubgol husk, along with sodium alginate, can be formulated into glidazide loaded microparticles, which can regulate blood glucose level in diabetic animal models (Sharma and Mazumder, 2014).

\section{Guar Gum}

Guar gum, a polysaccharide of galactose and mannose, obtained from the endosperms of an annual leguminous plant Cyamopsis tetragonoloba, is a biodegradable exo-polysaccharide, which doesn't cause harm to the environment after its disposal (Jain et al., 2005). Guar gum is fermented by a gram-negative obligate anaerobe Bacteroides ovatus present in the human colon (Tomlin et al., 1988). Two galactomannanases and one $\alpha$-galactosidase known as $\alpha$-galactosidase I are involved in the breakdown of guar gum by Bacteroides ovatus. The two galactomannanases cleave the $\beta$-mannan backbone of guar gum into large pieces whereas $\alpha$-galactosidase I removes galactose branches from the galactomannan segments. The backbone is further hydrolyzed by galactomannanases into single mannose residues (Valentine and Salyers, 1992). Extracellular enzymes of one strain of B.variabilis and one strain of B.uniformis degrade guar gum as well. On the other hand two strains of $B$. distasonis and B. thetaiotaomicron can ferment guar gum only after being treated by the aforesaid extracellular enzymes (Tomlin et al., 1986). It can be useful for the isolation and maintenance of thermophiles as it does not melt at temperatures as high as $70^{\circ} \mathrm{C}$ (Jain et al., 2005). Stable slants cannot be formed at room temperature with guar gum due to its high mobility and requires blending with other gelling agents (Jain, 2011). However, addition of cations or borax can improve the gelling properties of guar gum allowing it to be a suitable gelling agent for the growth of fungi and bacteria (Jain, 2011). Use of guar gum is restricted due to its inefficiency of self gellation and its high viscosity at higher temperature, which renders the dispensing of media to the petri plate difficult (Gangotri et al., 2012). It has less clarity due to the presence of impurities. In addition, due to its high adhesive property, it also hampers the isolation of microorganisms from a culture medium (Jain, 2011).

This non-ionic polysaccharide and its derivatives in various forms, such as coatings, matrix tablets, hydrogels and nanoparticles are often used in controlled release of therapeutics (Krishnaiah et al., 2002; Prabaharan, 2011; Aminabhavi and Nadagouda, 2014). In clinical trials, guar gum was reported to lower the serum cholesterol levels in patients with hypercholesterolaemia (Todd et al., 1990). Some other general applications of guar gum include paper sizing, thickener in syrups, protective colloid, stabilizer and as a binding and disintegrating agent in tablets. Its low cost makes it useful in plant tissue culture media (Babbar et al., 2005).

\section{Future Directions}

Several published alternatives of agar have not been studied very extensively for their properties. In fact, several physicochemical properties of different gums remain to be studied. Also the diversity of microorganisms that can be grown on them has been relatively unexplored. This might be achieved by using different gelling agents in combination than a single gelling agent. For example, a blend of Xanthan gum and agar in the ratio of 6:4 is recommended as an alternative to agar because of its suitability comparable to agar and cost advantage (Babbar and Jain, 2006). Alternative gelling agents like cassava flour, rice flour, corn flour, and potato starch in combination with agar is considered to be suitable for in vitro root regeneration (Daud et al., 2011) and we posit that they might have potential in microbial culture media too. Blending different gelling agents like guar gum, xanthan gum 
or isubgol with agar increases the viscosity and firmness of the media (Babbar and Jain, 2006).

There are several other sources that can be explored for gelling agents. We suspect that locust bean gum or carob gum, a galactomannan obtained from the seed endosperms of carob tree (Ceratonia siliqua), which has a wide range of applications in food (Ünal et al., 2003) and pharmaceutical industries (Brennan, 2005; Dionísio and Grenha, 2012) might find application as a gelling agent as well. Locust bean gum forms a viscous aqueous solution at relatively low concentration, which stabilizes emulsion and replaces fat in many food products. This unique characteristic makes it a very useful industrial gum. It is also non-ionic in nature and hence, solutions of locust bean gum are not influenced by $\mathrm{pH}$, salts and heat treatment (Barak and Mudgil, 2014). Through its synergistic actions with hydrocolloids such as carrageenan and xanthan gum, locust bean gum forms a gel with more elasticity and strength (Tako and Nakamura, 1986; Copetti et al., 1997). It has also been reported that it supports the growth of pluripotent embryonic stem cells in an undifferentiated state in mouse which makes it viable and a non-animal derived alternative to other gels (Perestrelo et al., 2014). Katira gum, a colloidal polysaccharide obtained

\section{References}

Abbott, I. A., and Chapman, F. A. (1981). Evaluation of kappa carrageenan as a substitute for agar in microbiological media. Arch. Microbiol. 128, 355-359. doi: 10.1007/BF00405912

Ackers, G. K., and Steere, R. L. (1962). Restricted diffusion of macromolecules through agar-gel membranes. Biochim. Biophys. Acta 59, 137-149. doi: 10.1016/0006-3002(62)90704-7

Aminabhavi, T. M., and Nadagouda, M. N. (2014). Guar gum as platform for the oral controlled release of therapeutics. Expert Opin. Drug Deliv. 11, 753-766. doi: 10.1517/17425247.2014.897326

Atici, T., Khawar, K. M., Ozel, C. A., and Katircioglu, H. (2008). Use of psyllium (isubgol) husk as an alternative gelling agent for the culture of prokaryotic microalgae (Cyanobacteria) Chroococcus limneticus Lemmermann and eukaryotic green microalgae (Chlorophyta) Scenedesmus quadricauda (Turpin) Brebisson. Afr. J. Biotechnol. 7, 1163-1167.

Babbar, S. B., and Jain, N. (1998). Isubgol'as an alternative gelling agent in plant tissue culture media. Plant Cell Reports 17, 318-322. doi: $10.1007 / \mathrm{s} 002990050400$

Babbar, S. B., and Jain, R. (2006). Xanthan gum: an economical partial substitute for agar in microbial culture media. Curr. Microbiol. 52, 287-292. doi: 10.1007/s00284-005-0225-5

Babbar, S. B., Jain, R., and Walia, N. (2005). Guar gum as a gelling agent for plant tissue culture media. In Vitro Cell. Develop. Biol. Plant 41, 258-261. doi: 10.1079/IVP2005628

Bannikova, G. E., Lopatin, S. A., Varlamov, V. P., Kuznetsov, B. B., Kozina, I. V., Miroshnichenko, M. L., et al. (2008). The thermophilic bacteria hydrolyzing agar: characterization of thermostable agarase. Prikl. Biokhim. Mikrobiol. 44, 404-409.

Barak, S., and Mudgil, D. (2014). Locust bean gum: processing, properties and food applications-a review. Int. J. Biol. Macromol. 66, 74-80. doi: 10.1016/j.ijbiomac.2014.02.017

Barbeyron, T., Gerard, A., Potin, P., and Henrissat, B. (1998). The kappacarrageenase of the marine bacterium Cytophaga drobachiensis. Structural and phylogenetic relationships within family-16 glycoside hydrolases. Mol. Biol. Evol. 15, 528-537. doi: 10.1093/oxfordjournals.molbev. a025952

Barbeyron, T., Michel, G., Potin, P., Henrissat, B., and Kloareg, B. (2000). iotaCarrageenases constitute a novel family of glycoside hydrolases, unrelated from the bark of Cochlospermum religiosum is used for plant cell culture (Jain and Babbar, 2002). It is transparent but its viscosity is significantly less than agar (Jain and Babbar, 2002), suggesting that it can be likely used in combination with agar. Welan gum, synthesized from Sphingomonas sp. (O’Neill et al., 1986), used in cement industry (Kaur et al., 2014), might also turn out to be a potential gelling agent. Starch sources from chickpea dextrose tapioca, corn, barley, potato and wheat have also been used as solidifiers for plant tissue culture (Sorvari, 1986a,b; Henderson and Kinnersley, 1988; Nene et al., 1996) but have not been explored as gelling agents in microbial media.

We hope for the speedy discovery of new gelling agents to cover the $\mathrm{pH}$ and temperature ranges that are not covered by the existing gelling agents. Work is required to find the reasons inhibition of certain microorganisms, if any, by the existing gelling agents and modifications to gelling agents to prevent their degradation by select group of microorganisms. Further research in the field is required to uncover newer insights of culturable microbes. In summary, there needs more progress in gelling agents to expand the range of culturable microbes and improve the quality of media. to that of kappa-carrageenases. J. Biol. Chem. 275, 35499-35505. doi: 10.1074/jbc.M003404200

Becker, A., Katzen, F., Pühler, A., and Ielpi, L. (1998). Xanthan gum biosynthesis and application: a biochemical/genetic perspective. Appl. Microbiol. Biotechnol. 50, 145-152. doi: 10.1007/s002530051269

Bellini, M. Z., and Caliari, C. (2014). Combining xanthan and chitosan membranes to multipotent mesenchymal stromal cells as bioactive dressings for dermo-epidermal wounds. J. Biomat. Appl. 29, 1155-1166. doi: 10.1177/0885328214553959

Brennan, C. S. (2005). Dietary fibre, glycaemic response, and diabetes. Mol. Nutr. Food Res. 49, 560-570. doi: 10.1002/mnfr.200500025

Cadmus, M. C., Jackson, L. K., Burton, K. A., Plattner, R. D., and Slodki, M. E. (1982). Biodegradation of Xanthan Gum by Bacillus sp. Appl. Environ. Microbiol. 44, 5-11.

Chen, J. T., Chang, C., and Chang, W. C. (1999). Direct somatic embryogenesis on leaf explants of Oncidium Gower Ramsey and subsequent plant regeneration. Plant Cell Reports 19, 143-149. doi: 10.1007/s002990050724

Copetti, G., Grassi, M., Lapasin, R., and Pricl, S. (1997). Synergistic gelation of xanthan gum with locust bean gum: a rheological investigation. Glycoconj. J. 14, 951-961. doi: 10.1023/A:1018523029030

Datta, S., Mody, K., Gopalsamy, G., and Jha, B. (2011). Novel application of $\kappa$-carrageenan: as a gelling agent in microbiological media to study biodiversity of extreme alkaliphiles. Carbohydr. Polym. 85, 465-468. doi: 10.1016/j.carbpol.2011.02.036

Daud, N., Taha, R. M., Noor, N., and Alimon, H. (2011). Provision of low cost media options for in vitro culture of Celosia sp. Afr. J. Biotechnol. 10, 18349-18355. doi: 10.4314/ajb.v10i80

Day, D. F., and Yaphe, W. (1975). Enzymatic hydrolysis of agar: purification and characterization of neoagarobiose hydrolase and p-nitrophenyl alphagalactoside hydrolase. Can. J. Microbiol. 21, 1512-1518. doi: 10.1139/m75-223

Dionísio, M., and Grenha, A. (2012). Locust bean gum: exploring its potential for biopharmaceutical applications. J. Pharm. Bioallied Sci. 4, 175. doi: 10.4103/0975-7406.99013

Fialho, A. M., Moreira, L. M., Granja, A. T., and Popescu, A. O. (2008). Occurrence, production, and applications of gellan: current state and perspectives. Appl. Microbiol. Biotechnol. 79, 889-900. doi: 10.1007/s00253-008-1496-0

Gangotri, W., Jain-Raina, R., and Babbar, S. B. (2012). Evaluation of guar gum derivatives as gelling agents for microbial culture media. World J. Microbiol. Biotechnol. 28, 2279-2285. doi: 10.1007/s11274-012-1027-0 
García-Ochoa, F., Santos, V. E., Casas, J. A., and Gómez, E. (2000). Xanthan gum: production, recovery, and properties. Biotechnol. Adv. 18, 549-579. doi: 10.1016/S0734-9750(00)00050-1

Gardin, H., and Pauss, A. (2001). x003BA;-carrageenan/gelatin gel beads for the co-immobilization of aerobic and anaerobic microbial communities degrading 2,4,6-trichlorophenol under air-limited conditions. Appl. Microbiol. Biotechnol. 56, 517-523. doi: 10.1007/s002530000581

Giavasis, I., Harvey, L. M., and McNeil, B. (2000). Gellan gum. Crit. Rev. Biotechnol. 20, 177-211. doi: 10.1080/07388550008984169

Greer, C. W., and Yaphe, W. (1984). Purification and properties of $\mathrm{l-carrageenase}$ from a marine bacterium. Can. J. Microbiol. 30, 1500. doi: 10.1139/ m84-239

Groleau, D., and Yaphe, W. (1977). Enzymatic hydrolysis of agar: purification and characterization of $\beta$-neoagarotetraose hydrolase from Pseudomonas atlantica. Can. J. Microbiol. 23, 672-679. doi: 10.1139/m77-100

Harding, N. E., Patel, Y. N., and Coleman, R. J. (2004). Organization of genes required for gellan polysaccharide biosynthesis in Sphingomonas elodea ATCC 31461. J. Indus. Microbiol. Biotechnol. 31, 70-82. doi: 10.1007/s10295-0040118-9

Harris, J. E. (1985). Gelrite as an agar substitute for the cultivation of mesophilic Methanobacterium and Methanobrevibacter species. Appl. Environ. Microbiol. 50, 1107-1109.

Henares, B. M. , Enriquez, E. P., Dayrit, F. M., and Rojas, N. R. L. (2010), Iota-carrageenan hydrolysis by Pseudoalteromonas carrageenovora IFO12985. Philipp. J. Sci. 139, 131-138.

Henderson, W. E., and Kinnersley, A. M. (1988). Corn starch as an alternative gelling agent for plant tissue culture. Plant Cell 15, 17-22. doi: 10.1007/bf00039885

Hou, C. T., Barnabe, N., and Greaney, K. (1986). Biodegradation of xanthan by salt-tolerant aerobic microorganisms. J. Ind. Microbiol. Biotechnol. 1, 31-37.

Huang, L.-C., Kohashi, C., Vangundy, R., and Murashige, T. (1995). Effects of common components on hardness of culture media prepared with gelrite x2122. In Vitro Cell. Develop. Biol. Plant 31, 84-89. doi: 10.1007/BF02632242

Jagdale, S. C., and Pawar, C. R. (2014). Application of design of experiment for polyox and xanthan gum coated floating pulsatile delivery of sumatriptan succinate in migraine treatment. Biomed. Res. Int. 2014:547212. doi: $10.1155 / 2014 / 547212$

Jain, N., and Babbar, S. B. (2002). Gum katira-a cheap gelling agent for plant tissue culture media. Plant Cell 71, 223-229.

Jain, N., Gupta, S., and Babbar, S. B. (1997). Isubgol as an alternative gelling agent for microbial culture media. J. Plant Biochem. Biotechnol. 6, 129-131. doi: 10.1007/BF03263024

Jain, R. (2011). Evaluation of blends of alternative gelling agents with agar and development of xanthagar, a gelling mix, suitable for plant tissue culture media. Asian J. Biotechnol 3, 153-164. doi: 10.3923/ajbkr.2011.153.164

Jain, R., Anjaiah, V., and Babbar, S. B. (2005). Guar gum: a cheap substitute for agar in microbial culture media. Lett. Appl. Microbiol. 41, 345-349. doi: 10.1111/j.1472-765X.2005.01760.x

Jamshidian, M., Savary, G., Grisel, M., and Picard, C. (2014). Stretching properties of xanthan and hydroxypropyl guar in aqueous solutions and in cosmetic emulsions. Carbohydr. Polym. 112, 334-341. doi: 10.1016/j.carbpol.2014. 05.094

Jansson, P. E., Lindberg, B., and Sandford, P. A. (1983). Structural studies of gellan gum, an extracellular polysaccharide elaborated by Pseudomonas elodea. Carbohydr. Res. 124, 135-139. doi: 10.1016/0008-6215(83)88361-X

Jianlong, W., and Yi, Q. (1999). Microbial degradation of 4-chlorophenol by microorganisms entrapped in carrageenan-chitosan gels. Chemosphere 38, 3109-3117. doi: 10.1016/S0045-6535(98)00516-5

Kang, K. S., Veeder, G. T., Mirrasoul, P. J., Kaneko, T., and Cottrell, I. W. (1982). Agar-like polysaccharide produced by a Pseudomonas species: production and basic properties. Appl. Environ. Microbiol. 43 1086-1091.

Kaur, V., Bera, M. B., Panesar, P. S., Kumar, H., and Kennedy, J. F. (2014). Welan gum: microbial production, characterization, and applications. Int. J. Biol. Macromol. 65, 454-461. doi: 10.1016/j.ijbiomac.2014.01.061

Kennedy, L., and Sutherland, I. W. (1994). Gellan lyases - novel polysaccharide lyases. Microbiology 140, 3007-3013.
Kirchmajer, D. M., Steinhoff, B., Warren, H., Clark, R., and in het Panhuis, M. (2014). Enhanced gelation properties of purified gellan gum. Carbohydr. Res. 388, 125-129. doi: 10.1016/j.carres.2014.02.018

Krishnaiah, Y., Karthikeyan, R. S., and Sankar, V. G. (2002). Three-layer guar gum matrix tablet formulations for oral controlled delivery of highly soluble trimetazidine dihydrochloride. J. Control. Release 81, 45-56. doi: 10.1016/S0168-3659(02)00031-7

Kubo, W. (2003). Oral sustained delivery of paracetamol from in situ-gelling gellan and sodium alginate formulations. Int. J. Pharm. 258, 55-64. doi: 10.1016/S0378-5173(03)00163-7

Kuo, S. M., Chang, S. J., Wang, H. Y., and Tang, S. C. (2014). Evaluation of the ability of xanthan gum/gellan gum/hyaluronan hydrogel membranes to prevent the adhesion of postrepaired tendons. Carbohydr. Polym. 114, 230-237. doi: 10.1016/j.carbpol.2014.07.049

Lin, C. C., and Casida, L. E. (1984). GELRITE as a gelling agent in media for the growth of thermophilic microorganisms. Appl. Environ. Microbiol. 47, 427-429.

Lines, A. D. (1977). Value of the $\mathrm{K}+$ salt of carageenan as an agar substitute in routine bacteriological media. Appl. Environ. Microbiol. 34, 637-639.

Manjanna, K. M., Kumar, P., and Shivakumar, B. (2010). Natural polysaccharide hydrogels as novel excipients for modified drug delivery systems: a review. Int. J. ChemTech Res. 2, 509-525.

Marteinsson, V. T., Birrien, J.-L., and Prieur, D. (1997). In situ enrichment and isolation of thermophillic microorganisms from deep-sea vent environments. Can. J. Microbiol. 43, 694. doi: 10.1139/m97-100

McLachlan, J. (1985). Macroalgae (seaweeds): industrial resources and their utilization. Plant Soil 89, 137-157. doi: 10.1007/BF02182240

McLean, M. W., and Williamson, D. R. (1979). chi-Carrageenase from Pseudomonas carrageenovora. Eur. J. Biochem. 93, 553-558. doi: 10.1111/j.1432-1033.1979.tb12854.x

Michel, G., Helbert, W., Kahn, R., and Dideberg, O. (2003). The structural bases of the processive degradation of l-carrageenan, a main cell wall polysaccharide of red algae. J. Mol. Biol. 334, 421-433. doi: 10.1016/j.jmb.2003. 09.056

Miyazaki, M., Nogi, Y., Ohta, Y., Hatada, Y., Fujiwara, Y., Ito, S., et al. (2008) Microbulbifer agarilyticus sp. nov. and Microbulbifer thermotolerans sp. nov., agar-degrading bacteria isolated from deep-sea sediment. Int. J. Syst. Evol. Microbiol. 58, 1128-1133. doi: 10.1099/ijs.0.65507-0

Morris, E. R., Nishinari, K., and Rinaudo, M. (2012). Gelation of gellan-a review. Food Hydrocoll. 28, 373-411. doi: 10.1016/j.foodhyd.2012.01.004

Muchová, M., Růzicka, J., Julinová, M., Dolezalová, M., Houser, J., Koutný, M., et al. (2009). Xanthan and gellan degradation by bacteria of activated sludge. Water Sci. Technol. 60, 965-973. doi: 10.2166/wst.2009.443

Nampoothiri, K. M., Singhania, R. R., and Sabarinath, C. (2003). Fermentative production of gellan using Sphingomonas paucimobilis. Process Biochem. 38, 1513-1519. doi: 10.1016/S0032-9592(02)00321-7

Nene, Y. L., Sheila, V. K., and Moss, J. P. (1996). Tapioca: a potential substitute for agar in the tissue culture media. Curr. Sci. 70, 493-494.

Ohta, Y., Nogi, Y., Miyazaki, M., Li, Z., Hatada, Y., Ito, S., et al. (2004). Enzymatic properties and nucleotide and amino acid sequences of a thermostable betaagarase from the novel marine isolate, JAMB-A94. Biosci. Biotechnol. Biochem. 68, 1073-1081. doi: 10.1271/bbb.68.1073

O’Neill, M. A., Selvendran, R. R., Morris, V. J., and Eagles, J. (1986). Structure of the extracellular polysaccharide produced by the bacterium Alcaligenes (ATCC 31555) species. Carbohydr. Res. 147, 295-313. doi: 10.1016/S00086215(00)90638-4

Ozel, C. A., Khawar, K. M., and Arslan, O. (2008). A comparison of the gelling of isubgol, agar and gelrite on in vitro shoot regeneration and rooting of variety Samsun of tobacco (Nicotiana tabacum L.). Sci. Hortic. 117, 174-181. doi: 10.1016/j.scienta.2008.03.022

Palaniraj, A., and Jayaraman, V. (2011). Production, recovery and applications of xanthan gum by Xanthomonas campestris. J. Food Eng. 106, 1-12. doi: 10.1016/j.jfoodeng.2011.03.035

Paul, F., Morin, A., and Monsan, P. (1986). Microbial polysaccharides with actual potential industrial applications. Biotechnol. Adv. 4, 245-259. doi: 10.1016/0734-9750(86)90311-3 
Perestrelo, A. R., Grenha, A., and da Costa, A. (2014). Locust bean gum as an alternative polymeric coating for embryonic stem cell culture. Mater. Sci. Eng. C Mater. Biol. Appl. 40, 336-344. doi: 10.1016/j.msec.2014.04.022

Petrovski, S., and Tillett, D. (2012). Back to the kitchen: food-grade agar is a low-cost alternative to bacteriological agar. Anal. Biochem. 429, 140-141. doi: 10.1016/j.ab.2012.07.011

Poppe, J. (1997). “Gelatin," in Thickening and Gelling Agents for Food, ed A. P. Imeson (Boston, MA: Springer US), 144-168.

Potin, P., Sanseau, A., Le Gall, Y., Rochas, C., and Kloareg, B. (1991). Purification and characterization of a new kappa-carrageenase from a marine Cytophagalike bacterium. Eur. J. Biochem. 201, 241-247.

Prabaharan, M. (2011). Prospective of guar gum and its derivatives as controlled drug delivery systems. Int. J. Biol. Macromol. 49, 117-124. doi: 10.1016/j.ijbiomac.2011.04.022

Prajapati, V. D., Jani, G. K., Zala, B. S., and Khutliwala, T. A. (2013). An insight into the emerging exopolysaccharide gellan gum as a novel polymer. Carbohydr. Polym. 93, 670-678. doi: 10.1016/j.carbpol.2013.01.030

Razavi, M., Nyamathulla, S., and Karimian, H. (2014). Hydrogel polysaccharides of tamarind and xanthan to formulate hydrodynamically balanced matrix tablets of famotidine. Molecules 19, 13909-13931. doi: 10.3390/molecules1909 13909

Sá-Correia, I., Fialho, A. M., Videira, P., Moreira, L. M., Marques, A. R., and Albano, H. (2002). Gellan gum biosynthesis in Sphingomonas paucimobilis ATCC 31461: genes, enzymes and exopolysaccharide production engineering. J. Indus. Microbiol. Biotechnol. 29, 170-176. doi: 10.1038/sj.jim.7000266

Sahay, S. (1999). The use of psyllium (isubgol) as an alternative gelling agent for microbial culture media. World J. Microbiol. Biotechnol. 15, 733-735. doi: 10.1023/A:1008954128637

Sakai, M., Hosoda, A., and Ogura, K. (2014). The growth of Steroidobacter agariperforans sp. nov., a novel agar-degrading bacterium isolated from soil, is enhanced by the diffusible metabolites produced by bacteria belonging to Rhizobiales. Microbes Environ. 29, 89-95. doi: 10.1264/jsme2.ME13169

Schmidt, D., and Rath, P.-M. (2003). Faster genetic identification of medically important aspergilli by using gellan gum as gelling agent in mycological media. J. Med. Microbiol. 52, 653-655. doi: 10.1099/jmm.0.05135-0

Sharma, V. K., and Mazumder, B. (2014). Gastrointestinal transition and antidiabetic effect of Isabgol husk microparticles containing gliclazide. Int. J. Biol. Macromol. 66, 15-25. doi: 10.1016/j.ijbiomac.2014.02.014

Shigeta, J.-I., Sato, K., Tanaka, S., Nakayama, M., and Mii, M. (1996). Efficient plant regeneration of asparagus by inducing normal roots from in vitro multiplied shoot explants using gellan gum and glucose. Plant Sci. 113, 93-104. doi: 10.1016/0168-9452(95)04273-3
Shimomura, K., and Kamada, H. (1986). Roles of gelling agents in plant tissue culture. Plant Tissue Cult. Lett. 3:38. doi: 10.5511/plantbiotechnology1984.3.38

Shungu, D., Valiant, M., and Tutlane, V. (1983). Gelrite as an agar substitute in bacteriological media. Appl. Environ. Microbiol. 46, $840-845$.

Sorvari, S. (1986a). Comparison of anther cultures of barley cultivars in barley-starch and agar gelatinized media. Ann. Agric. Fenn. 25, 249-254.

Sorvari, S. (1986b). The effect of starch gelatinized nutrient media in barley anther cultures. Ann. Agric. Fenn. 25, 127-133.

Stanier, R. Y. (1941). Studies on marine agar-digesting bacteria. J. Bacteriol. 42, 527-559.

Todd, P. A., Benfield, P., and Goa, K. L. (1990). Guar gum. Drugs 39, 917-928. doi: 10.2165/00003495-199039060-00007

Tako, M., and Nakamura, S. (1986). Synergistic interaction between kappacarrageenan and locust-bean gum in aqueous media. Agric. Biol. Chem. 50, 2817-2822. doi: 10.1271/bbb1961.50.2817

Tomlin, J., Read, N. W., Edwards, C. A., and Duerden, B. I. (1986). The degradation of guar gum by a faecal incubation system. Br. J. Nutr. 55, 481-486. doi: 10.1079/BJN19860055

Tomlin, J., Read, N. W., Edwards, C. A., and Duerden, B. I. (1988). The digestion of guar gum by individual strains of colonic bacteria. Microb. Ecol. Health Disease 1. doi: 10.3402/mehd.v1i3.7411

Ünal, B., Metin, S., and Işıklı, N. D. (2003). Use of response surface methodology to describe the combined effect of storage time, locust bean gum and dry matter of milk on the physical properties of low-fat set yoghurt. Int. Dairy J. 13, 909-916. doi: 10.1016/S0958-6946(03)00118-3

Valentine, P. J., and Salyers, A. A. (1992). Analysis of proteins associated with growth of Bacteroides ovatus on the branched galactomannan guar gum. Appl. Environ. Microbiol. 58, 1534-1540.

Conflict of Interest Statement: The authors declare that the research was conducted in the absence of any commercial or financial relationships that could be construed as a potential conflict of interest.

Copyright (C) 2015 Das, Tripathi, Basu, Bose, Maitra and Khurana. This is an openaccess article distributed under the terms of the Creative Commons Attribution License (CC BY). The use, distribution or reproduction in other forums is permitted, provided the original author(s) or licensor are credited and that the original publication in this journal is cited, in accordance with accepted academic practice. No use, distribution or reproduction is permitted which does not comply with these terms. 